\title{
Acute left flank pain
}

\author{
Beatrice Hoffmann
}

Received: 14 February 2009 / Accepted: 2 May 2009 /Published online: 29 May 2009

(C) Springer-Verlag London Ltd 2009

Bedside ultrasound is becoming a very important tool in emergency medicine. One of the staples of bedside ultrasound is its potential in assisting the clinician with information on local anatomy and organ function.

A previously healthy 44 -year-old male presented to the emergency department with acute dysuria and left flank pain. A renal bedside ultrasound was obtained and showed excellent urine flow into the bladder from bilateral duplicated ureters (Fig. 1) and no hydronephrosis. An acute ureteral obstruction was therefore excluded.

The patient was subsequently diagnosed with a urinary tract infection in the setting of duplex collecting system. No renal calculus was detected on computed tomography.

He received antibiotic and fluid hydration management in the emergency department and was discharged with close outpatient urology follow-up.

Complete ureteral duplication is a rare condition occurring in about $0.2-0.8 \%$ of the population [1-3] and is often detected incidentally. A symptomatic patient can present with findings such as ureteropelvic junction obstruction, vesicoureteric reflux, or urinary tract infection resulting in parenchymal scarring [1-3]. Patients with this diagnosis require close urology follow-up for thorough renal and collecting system assessment. Therapeutic or prophylactic surgical intervention and prophylactic treatment with antibiotics might be indicated to prevent renal dysfunction [1-5].

\footnotetext{
B. Hoffmann $(\triangle)$

Department of Emergency Medicine, Johns Hopkins Medical Institutions, 1830 E. Monument Street, Suite 6-100, Baltimore, MD 21287, USA

e-mail: Bhoffma8@jhmi.edu
}

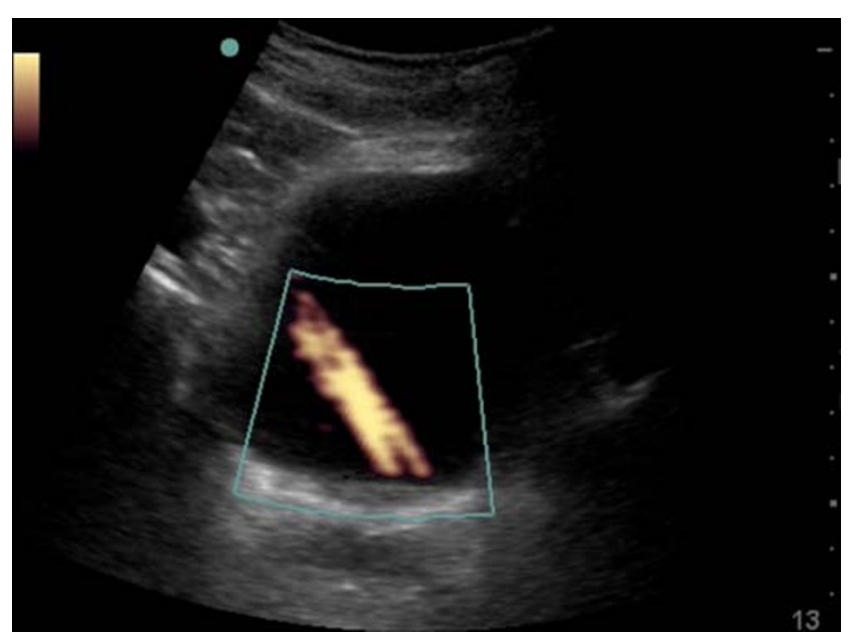

Fig. 1 Bladder ultrasound using power Doppler and B-mode: the still image shows a strong ureteral flow into the bladder from the left duplicated ureteral os

\section{References}

1. Fernbach SK, Feinstein KA, Spencer K, Lindstrom CA (1997) Ureteral duplication and its complications. Radiographics 17 (1):109-127

2. Schlussel RN, Retik AB (2002) Ectopic ureter, ureterocele, and other anomalies of the ureter. In: Walsh PC (ed) Campbell's urology. Saunders, Philadelphia, pp 2007-2052

3. Chacko JK, Koyle MA, Mingin GC, Furness PD 3rd (2007) Ipsilateral ureteroureterostomy in the surgical management of the severely dilated ureter in ureteral duplication. J Urol 178(4 Pt 2):1689-1692

4. Afshar K, Papanikolaou F, Malek R, Bagli D, Pippi-Salle JL, Khoury A (2005) Vesicoureteral reflux and complete ureteral duplication. Conservative or surgical management? J Urol 173 (5):1725-1727

5. Hensle TW, Hyun G, Grogg AL, Eaddy M (2007) Part 2: Examining pediatric vesicoureteral reflux: a real-world evaluation of treatment patterns and outcomes. Curr Med Res Opin 23(Suppl 4):S7-S13 